\title{
Nutritional Anaemia and Obesity in the EMR: The protective role of Breastfeeding for two years
}

\author{
Azza Abul-Fadl, M.D.*, Afaf Tawfik MD**, Ayoub Al-Jawaldeh Ph.D.*** \\ Pediatric Department, Banha Faculty of Medicine, Benha University, Benha 13511, Egypt* \\ National Nutrition Institute, Cairo 11562, Cairo, Egypt** \\ Department of Nutrition Sciences', University of Vienna, Viena A-1090, Austria***
}

\begin{abstract}
Background: The preexistence of obesity with nutritional anaemia is becoming an increasing problem in the Eastern Mediterranean Region (EMR). Much controversy exists around the role of continued breastfeeding in alleviating the health and survival consequences of these problems in the region.
\end{abstract}

Aim: To examine trends and relationships of nutritional anaemia (NA) in women and children underfive years of age (CU5) with obesity and breastfeeding practices in the EMR.

Methods: Data from regional database banks of WHO and UNICEF for anaemia in pregnant and nonpregnant women and CU5 from 22 countries in EMR were retrieved, compiled, and statistically analyzed. Breastfeeding indicators for timely first suckle (TFS), exclusive breastfeeding (EBF) and continued breastfeeding for 12 (BFC12) and 24 months (BFC24), low-birth-weight (LBW), stunting, overweight, total fertility rates (TFR) and mortality rates (MR) were correlated with nutritional anaemia and analyzed by income groups into 5 low income countries (LIC), 11 middle income countries (MIC) and 6 high income countries (HIC).

Results: Trends in mean prevalence of anaemia in women showed a concave curve increasing after a short decrease in the early 2000 in all income groups $(\mathrm{P}>0.05)$. Trends in anaemia in the CU5 exhibited a steep decrease from a mean of $52.59 \pm 16.4$ in 2000 to $37.3 \pm 14.9$ in 2016 at $\mathrm{P}<0.002$, the steep decline was significant in HIC $(\mathrm{P}<0.01)$ and MIC $(\mathrm{P}<0.02)$, but not for LIC $(\mathrm{P}>0.05)$. Anaemia prevalence in women and CU5 was significantly correlated to LBW, stunting, and with overweight and obesity in adults but negatively in CU5. All age specific MRs were highly correlated with anaemia in pregnant, non-pregnant and CU5 at $\mathrm{P}<0.001$ and TFR at $\mathrm{P}<0.05$. BFC for shorter durations was negatively correlated with anaemia in pregnant women $(\mathrm{r}-0.5)$ at $\mathrm{P}<0.05$ and was positively correlated in MIC and HIC. In non-pregnant women, BFC12 and BFC 24 correlated positively with anaemia prevalence in all three income groups at $\mathrm{P}<0.01$.

Conclusions: Completing optimal breastfeeding for two years should be promoted to protect women and CU5 from anemia and obesity. Nutritional anemia during pregnancy increases regional rates of LBW, stunting and mortality. Spacing out births by encouraging longer duration of breastfeeding, to replenish iron stores, can help alleviate many of the health and nutritional problems in the region. 
Key words: breastfeeding; mortality; obesity; overweight; stunting; wasting; education; life expectancy

\section{Disclosures: None}

\section{Background}

Iron deficiency anaemia (IDA) is the most common among nutritional anaemias (NA) at a global level in both industrialized and developing countries, affecting one third of the world's population ${ }^{(1)}$. It is estimated that 800 million children and women are affected by IDA ${ }^{(2)}$. In the Eastern Mediterranean Region (EMR) where a high proportion of women become anemic during pregnancy $(3,4,5)$, the problem is magnified because of the coexistence of infectious diseases and malnutrition problems as stunting, overweight and obesity ${ }^{\left({ }^{(6)}\right.}$. Estimates from the World Health Organization (WHO) recent report showed that from $27 \%$ to $61 \%(40 \%$ on average) of pregnant women in the EMR countries are anemic (1). However, many of these women were already anemic at the time of conception, with an estimated prevalence of IDA of $34.4 \%$ in nonpregnant women in the EMR countries ${ }^{(3,4)}$. The prevalence of iron deficiency without anaemia (IDWA) characterized by low serum ferritin and sparse or absent stainable iron in bone marrow, is far greater than the prevalence of IDA which often develops during the later stages of pregnancy even in women who enter pregnancy with relatively adequate iron stores ${ }^{(4,5)}$.

There are many gaps in our knowledge about the adverse effects of maternal IDA and IDWA on pregnancy outcome especially in relation to low birth weight ${ }^{(7)}$. Both underweight and overweight in pregnancy influence outcome and are associated with LBW ${ }^{(8)}$. However despite the prevalence of undernutrition and overweight in low income and developing countries ${ }^{(9)}$, this link with anaemia and pregnancy outcome is not clear. The differences in outcomes of anaemia during pregnancy prevent policy makers from taking decisions about the needs for supplementation of pregnant women and breastfed babies. Also there is controversy as to whether pregnant women, nursing mothers and breastfed babies need to be supplemented with iron ${ }^{(\mathbf{1 0})}$. There is fear that prolonging the duration of breastfeeding may increase the risk of IDA among infants ${ }^{(11)}$. Moreover there is not enough evidence to verify the protective role of lactation against the development of IDA both in mothers and babies. Other workers have shown that prolonged breastfeeding may not cause growth faltering but it is the quality and adequacy of complementary feeding and this reverse causality may be reversed is influenced by the pattern of infant feeding once weaning foods are introduced ${ }^{(\mathbf{1 2})}$. Some studies have shown that supplementation during pregnancy may not be necessary (13) 
and may increase the risk of LBW and on the contrary others suggest that supplementation is recommended ${ }^{(14)}$. Furthermore some workers suggest that breastfeeding is protective for infants ${ }^{(15,16)}$ and for the breastfeeding mother by preserving and building her iron stores. This is achieved by enhancing absorption of iron and preventing blood loss and inducing lactational amenorrhea ${ }^{(17)}$. Whereas introduction of formula may predispose to IDA from cow's milk allergy and poor iron absorption ${ }^{(18)}$.

There is lots of controversy around the need for iron supplementation during pregnancy and infants. Another poorly investigated and controversial issue in literature is the outcome of prolonged breastfeeding on NA and the health of mothers and infants. It is not clear how breastfeeding and obesity are linked with NA. We test the hypothesis of whether prolonging breastfeeding, especially in populations living in emergency situations, may be actually reducing the burden of anaemia and its consequences to mothers and children.

\section{Methods}

Study Design: This is a retrospective review study. We used the data from the World Health Organization (WHO), Eastern Mediterranean Region (EMR) Framework for health information systems and core indicators for monitoring health situation and health system performance ${ }^{(19)}$ for the 22 countries of the EMR region. Missing data was completed from the UNICEF Multicenter Indicator Cluster Surveys (MICS) of UNICEF accessed on mics.unicef.org ${ }^{(20)}$. The results from the most recent MICS surveys are becoming progressively available online and are updated for countries every 3 to 5 years. The data for life expectancy were retrieved from the WHO World Health Statistics 2016 Monitoring Health for SDGs (Sustainable Development Goals) (WHO, 2016) (21).

Selection of data: This study focused on the 22 countries in the EMR. These countries are included in the region based on the request of the heads of member states who decide which region they wish to become affiliated with. They present their request to the WHO regional committee, which decides the list of countries included within each region. Hence the EMR is represented by 22 countries that include Afghanistan, Bahrain, Djibouti, Egypt, Jordan, Iran, Iraq, Kuwait, Lebanon, Libya, Morocco, the occupied territory of Palestine, Oman, Pakistan, Qatar, Saudi Arabia, Somalia, Sudan, Syria, Tunisia, the United Arab Emirates, and Yemen (in alphabetical order).

The countries were classified by income group into three groups: 
High income countries (HIC) included Bahrain, Kuwait, Qatar, Saudi Arabia, United Arab Emirates (UAE) and Oman.

Middle income countries (MIC) included Egypt, Jordan, Iran, Iraq, Lebanon, Libya, Morocco, Syria, Tunisia, Pakistan, and occupied territory of Palestine.

Low income countries (LIC) included Afghanistan, Djibouti, Somalia, Sudan and Yemen.

\section{Data analysis:}

Nutritional anemia (NA) for pregnant women (NAP) and non-pregnant women (NANP) and NA in children under-five years of age (CU5) for the 22 countries of the EMR were retrieved from WHO database banks and World Bank statistics $(\mathbf{1 8}, \mathbf{1 9}, \mathbf{2 1 )}$. They were correlated to breastfeeding rates for timely first suckle (TFS), exclusive breastfeeding (EBF), continued breastfeeding (CBF) for 12 and 24 months in children under-five years of age (CU5) and adults. The data represented surveys that were conducted over the past 10 to 15 years from 2000 to 2015. TFS is defined as early initiation of breastfeeding within the first hour immediately after birth.

The rates for EBF were retrieved from data bases of the UNICEF and WHO. They represented the pattern of feeding only on mother's milk from birth up to 5 months of age (05 months) with no introduction of bottles, pacifiers, drinks or other milks or even water (except for medicine or vitamin drops). CBF12 and CBF24 were defined as breastfeeding at this age irrespective of frequency or duration of breastfeeding.

Other data collected included: percent children U5 who were overweight, obese or stunted, adults (+18 years of age) who are overweight and obese and population growth rate (PGR) and total fertility rate (TFR). Also mortality rates including: neonatal mortality rate (NMR), infant mortality rate (IMR), under-five mortality rate (U5MR), maternal mortality ratio (MMR) and non-communicable disease related mortality (NCD-MR).

Ethical considerations: The work of the paper was in compliance with the ethical principles of Helsinki Declaration (1964). ${ }^{(14)}$

Statistical Analysis: The collected data were organized, tabulated and statistically analyzed using SPSS version 20 (SPSS Inc; Chicago, Illinois). Discrete data were presented in range, mean and standard deviation. Student t-test (for parametric data) and Mann-Whitney U test 
(for non-parametric data) were used for comparison of 2 distinct groups. Analysis of variance was used to compare country groups. Spearman rank correlation coefficient (r) was used to measure the strength and direction of the linear relationship between two variables. The pvalue was used to determine the level of significance at a cut-off of $\mathrm{P}<0.05$.

\section{Results}

Table (1) Trends in the prevalence rates of anaemia in pregnant and non-pregnant women and children under-five years of age between the year 2000 and 2016 by income group in countries of EMR

\begin{tabular}{|c|c|c|c|c|c|c|c|c|}
\hline $\begin{array}{c}\text { Anaemia } \\
\text { Prevalenc } \\
\text { e rates }\end{array}$ & & in 200 & & & 2016 & & $\begin{array}{c}\text { Mean } \\
\text { rates in } \\
2000\end{array}$ & $\begin{array}{c}\text { Mean } \\
\text { rates in } \\
2016\end{array}$ \\
\hline $\begin{array}{l}\text { Income } \\
\text { group }\end{array}$ & LIC (5) & $\begin{array}{l}\text { MIC } \\
\text { (11) }\end{array}$ & HIC (6) & LIC (5) & MIC (11) & HIC (6) & \multicolumn{2}{|c|}{ All countries } \\
\hline $\begin{array}{l}\text { Women } \\
\text { mean } \pm \text { SD }\end{array}$ & $\begin{array}{r}42.58 \\
+10.3 \\
\end{array}$ & $\begin{array}{l}34.03^{*} \\
+5.8\end{array}$ & $\begin{array}{l}34.6^{* *} \\
\pm 10.01 \\
\end{array}$ & $\begin{array}{r}43.88 \\
+15.5 \\
\end{array}$ & $\begin{array}{l}33.74 \\
\pm 6.3\end{array}$ & $\begin{array}{r}33.7 \\
+8.3 \\
\end{array}$ & $\begin{array}{l}35.78 \\
+8.7\end{array}$ & $\begin{array}{l}35.97 \\
+10.12 \\
\end{array}$ \\
\hline $\begin{array}{l}\text { Children } \\
\text { mean } \pm S D\end{array}$ & $\begin{array}{l}75.4 \\
\pm 10.6\end{array}$ & $\begin{array}{l}50.5 \\
\pm 13.6\end{array}$ & $\begin{array}{l}44 \\
\pm 9.6\end{array}$ & $\begin{array}{l}57 \\
\pm 16.4\end{array}$ & $\begin{array}{l}34.4^{* *} \\
\pm 11.2\end{array}$ & $\begin{array}{l}30.67^{*} \\
\pm 5.9\end{array}$ & $\begin{array}{l}52.59 \\
\pm 15.69\end{array}$ & $\begin{array}{l}37.32^{* * *} \\
\pm 14.9\end{array}$ \\
\hline
\end{tabular}

$P$-value (level of statistical significance from 2000 to 2016 in each income group: ${ }^{* * *} P<0.002,{ }^{* *} P<0.01$, ${ }^{*} \mathrm{P}<0.02$, non- significant $\mathrm{P}>0.05$. Women in the reproductive age group (15-49 years) include pregnant and non-pregnant. CU5: Children under-five years of age, LIC: low income countries, MIC: middle income countries, HIC: high income countries.

Table (2) Relationship between anaemia during pregnancy and non-pregnant and anaemia among the children under-five years of age with indices for low-birth-weight, stunting, overweight and obesity in EMR countries:

\begin{tabular}{|c|c|c|c|c|}
\hline Nutrition Indices & $\begin{array}{l}\text { Mean } \\
\pm \text { SD }\end{array}$ & $\begin{array}{l}\text { Anaemia during } \\
\text { pregnancy }\end{array}$ & $\begin{array}{l}\text { Anaemia in non- } \\
\text { pregnant }\end{array}$ & $\begin{array}{l}\text { Anaemia in under } \\
\text { fives }\end{array}$ \\
\hline \multicolumn{5}{|c|}{ In children under-five years of age } \\
\hline - $\quad$ Low Birth Weight & $\begin{array}{l}14.14 \\
\pm 10.1\end{array}$ & $\mathrm{r} 0.72 * * *$ & $\mathrm{r} 0.72 * * *$ & $0.66 * * *$ \\
\hline - $\quad$ Stunting & $\begin{array}{l}19.69 \\
\pm 14.5\end{array}$ & $\mathrm{r} 0.81^{* * *}$ & $\mathrm{r} 0.704^{* * *}$ & $\mathrm{r} 0.72^{* * *}$ \\
\hline $\begin{array}{ll}- & \text { Anaemia in } \\
& \text { under-fives } \\
\end{array}$ & $\begin{array}{r}40.58 \\
+16.39 \\
\end{array}$ & $\mathrm{r} 0.74^{* * *}$ & r0.52* & - \\
\hline - $\quad$ Overweight & $\begin{array}{c}9.11 \\
+5.87\end{array}$ & $r-0.62^{* * *}$ & $r-0.44^{* *}$ & $r-0.31$ \\
\hline - Obesity & $\begin{array}{c}3.2 \\
+3.89\end{array}$ & $r-0.53^{*}$ & $r-0.47^{* *}$ & $r-0.35$ \\
\hline \multicolumn{5}{|l|}{ In Adults (18+ years) } \\
\hline - Obesity & $\begin{array}{r}24.69 \\
+11.9\end{array}$ & $\mathrm{r} 0.602 * *$ & $\mathrm{r} 0.7^{* * *}$ & $\mathrm{r}-0.68^{* * *}$ \\
\hline - Overweight & $\begin{array}{r}55.44 \\
+19.13 \\
\end{array}$ & $r-0.83^{* *}$ & $\mathrm{r} 0.3$ & $\mathrm{r}-0.66^{* * *}$ \\
\hline
\end{tabular}




\begin{tabular}{|c|c|c|c|c|c|}
\hline - & $\begin{array}{l}\text { Population } \\
\text { growth }\end{array}$ & $\begin{array}{r}4.4 \\
+2.75 \\
\end{array}$ & $r-0.25$ & $r-0.227$ & $r-0.122$ \\
\hline - & $\begin{array}{l}\text { Total Fertility } \\
\text { rates (TFR) }\end{array}$ & $\begin{array}{r}3.27 \\
+1.3\end{array}$ & $r-0.25$ & R0.38* & $r-0.122$ \\
\hline
\end{tabular}

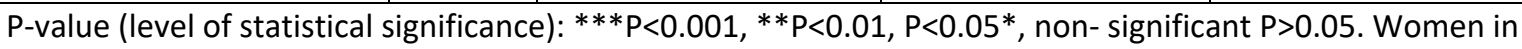
the

Table (3) Correlative studies between prevalence rates of anaemia in the pregnant women and non-pregnant with mortality rates for children and maternal mortality ratio in EMR countries:

\begin{tabular}{|c|c|c|c|c|}
\hline Mortality rates & $\begin{array}{l}\text { Mean } \\
\pm \text { SD }\end{array}$ & $\begin{array}{c}\text { Anaemia in } \\
\text { pregnant women }\end{array}$ & $\begin{array}{c}\text { Anaemia in non- } \\
\text { pregnant }\end{array}$ & $\begin{array}{l}\text { Anaemia in } \\
\text { under fives }\end{array}$ \\
\hline - NMR & $\begin{array}{r}15.5 \\
+13.27 \\
\end{array}$ & $\mathrm{r} 0.73^{* *}$ & $\mathrm{r} 0.66^{* *}$ & $r 0.63^{* *}$ \\
\hline - IMR & $\begin{array}{r}24.86 \\
+22.63 \\
\end{array}$ & $\mathrm{r} 0.9^{* *}$ & $\mathrm{r} 0.62^{* *}$ & $\mathrm{r} 0.9^{* *}$ \\
\hline - U5MR & $\begin{array}{r}33.04 \\
+34.53 \\
\end{array}$ & $\mathrm{r} 0.7^{* *}$ & r0.9** & $r 0.73^{* *}$ \\
\hline - $\quad$ MMR & $\begin{array}{r}126.54 \\
+183.0 \\
\end{array}$ & $r 0.76^{* *}$ & $\mathrm{r} 0.62^{* *}$ & r0.56* \\
\hline
\end{tabular}

P-value (level of statistical significance): ${ }^{* * P}<0.001,{ }^{*} P<0.01$, non-significant $P>0.05$. NMR: neonatal mortality rate, IMR: infant mortality rate, U5MR: under-five mortality rate, MMR: maternal mortality ratio.

Table (4) Relationship between anaemia in pregnant and non-pregnant women with timely initiation of breastfeeding, exclusive breastfeeding and continued breastfeeding rates for 12 and 24 months in the EMR countries

\begin{tabular}{|c|c|c|c|c|c|c|c|c|}
\hline \multirow{2}{*}{\multicolumn{2}{|c|}{$\begin{array}{l}\text { Breastfeeding } \\
\text { indicators } \\
\text { Anaemia in } 22 \text { countrie }\end{array}$}} & \multicolumn{2}{|c|}{$\begin{array}{l}\text { Timely Initiation } \\
\text { of breastfeeding }\end{array}$} & \multicolumn{2}{|c|}{$\begin{array}{l}\text { Exclusive } \\
\text { breastfeeding }(0-5 \mathrm{mo})\end{array}$} & \multicolumn{2}{|c|}{$\begin{array}{l}\text { Breastfeeding } \\
(12 \mathrm{mo})\end{array}$} & $\begin{array}{l}\text { Breastfeeding } \\
(24 \mathrm{mo})\end{array}$ \\
\hline & & & & & & & & \\
\hline \multicolumn{2}{|c|}{$\begin{array}{l}\text { Anaemia prevalence } \\
\text { during pregnancy } \\
(2015)\end{array}$} & & r0.10 & \multicolumn{2}{|l|}{ r0.07 } & \multicolumn{2}{|c|}{ r 0.49* } & r 0.51* \\
\hline \multicolumn{2}{|c|}{$\begin{array}{l}\text { Anaemia prevalence in } \\
\text { non-pregnant (2015) }\end{array}$} & & r0.23 & \multicolumn{2}{|l|}{ r0.17 } & \multicolumn{2}{|c|}{ r0.36 } & r 0.34 \\
\hline \multicolumn{2}{|c|}{$\begin{array}{l}\text { Anaemia prevalence in } \\
\text { the under-five (2015) }\end{array}$} & & r0.19 & \multicolumn{2}{|l|}{ r0.03 } & \multicolumn{2}{|r|}{ r0.36 } & r0.46 \\
\hline \multicolumn{2}{|l|}{ Low birth weight } & & $r-0.04$ & \multicolumn{2}{|l|}{ r0.025 } & \multicolumn{2}{|c|}{ r0.48* } & r0.52* \\
\hline \multicolumn{2}{|c|}{$\begin{array}{l}\text { Anaemia prevalence in } \\
\text { pregnant \& non- } \\
\text { pregnant (2016) }\end{array}$} & & r0.05 & \multicolumn{2}{|l|}{$r-0.11$} & \multicolumn{2}{|c|}{ r0.44* } & $\mathrm{r} 0.63^{* *}$ \\
\hline \multicolumn{9}{|c|}{$\begin{array}{l}\text { P-value (level of statistical significance): } * * P<0.001, * P<0.01, \text { not significant } P>0.05 \text {. } \\
\text { - Combined prevalence of anaemia in both pregnant }(\mathrm{Hb}<10 \mathrm{~g} / \mathrm{dl}) \text { and non-pregnant }(\mathrm{Hb}<12 \mathrm{gdl}) \\
\text { - }(\mathrm{r}) \text { correlation coefficient using Pearsons method }\end{array}$} \\
\hline \multicolumn{9}{|c|}{$\begin{array}{l}\text { Table (5) Correlations between anaemia in pregnant, nonpregnant women and children under-five } \\
\text { with breastfeeding continuity for } 12 \text { and } 24 \text { months of age by level of income in the EMR countries }\end{array}$} \\
\hline \multirow{2}{*}{$\begin{array}{l}\text { Duration of } \\
\text { Breastfeeding }\end{array}$} & \multicolumn{4}{|c|}{ Breastfeeding (12 mo) } & \multicolumn{4}{|c|}{ Breastfeeding (24 mo) } \\
\hline & LIC (5) & & MIC (11) & HIC (6) & 니 (5 & & MIC (11) & HIC (6) \\
\hline $\begin{array}{l}\text { Anaemia in } \\
\text { pregnant }\end{array}$ & $\mathrm{r}-0$. & & r0.35 & r0.43* & $r-0$. & $5 * *$ & r0.798** & $r-0.08$ \\
\hline
\end{tabular}




\begin{tabular}{|l|c|c|c|c|c|c|}
\hline $\begin{array}{l}\text { Anaemia in } \\
\text { non-pregnant }\end{array}$ & $r 0.87^{* *}$ & $r 0.7^{* *}$ & $r 0.36$ & $r 0.65^{* *}$ & $r 0.46^{*}$ & $r 0.725^{* *}$ \\
\hline $\begin{array}{l}\text { Anaemia in } \\
\text { under-fives }\end{array}$ & $\mathrm{r}-0.05$ & $\mathrm{r} 0.56^{*}$ & $\mathrm{r} 0.59 *$ & $\mathrm{r}-0.16$ & $\mathrm{r} 0.8^{* *}$ & $\mathrm{r0.56*}$ \\
\hline
\end{tabular}

P-value (level of statistical significance): ${ }^{*} \mathrm{P}<0.001,{ }^{*} \mathrm{P}<0.01$, non- significant $\mathrm{P}>0.05$.

LIC: Afghanistan, Djibouti, Somalia, Sudan, Yemen.

MIC: Egypt, Jordan, Iran, Iraq, Lebanon, Libya, Morocco, Syria, Tunisia, Pakistan, Palestine.

HIC: Bahrain, Kuwait, Qatar, Saudi Arabia, UAE, Oman.

\section{Results}

I- Current status and trends in anaemia prevalence: The overall mean and standard deviation prevalence of anaemia for women in the reproductive age group (15 to 49 years) in the EMR was $35.97 \pm 10.12$ in 2016 with no change in the mean prevalence from the year 2000 of $35.78 \pm 8.7(\mathrm{t}=0.07)$ at $\mathrm{P}>0.05$. Mean prevalence of anaemia in CU5 in EMR was $37.3 \pm 14.9$ in 2016 and decreased steeply and significantly from a mean prevalence of $52.59 \pm 15.69$ in $2000(\mathrm{t}=3.31)$ at $\mathrm{P}<0.002$ as shown in table (1).

The trends in the prevalence rates of NAP, NANP and NA in CU5 between the year 2000 and 2016 by income groups of LIC, MIC, HIC of the countries of EMR are shown in table (1) as follows:

- In the LIC: the prevalence of anaemia among women in the reproductive age group (1549 years) decreased from a mean of $42.58 \pm 10.3$ in the year 2000 to a mean of $43.88 \pm 15.5$ in the year $2016(\mathrm{t}$-test $=0.15)$ at $\mathrm{P}>0.05$. While the prevalence of anaemia in CU5 dropped from a mean of $75 \pm 10.6$ in the year 2000 to a mean of $57 \pm 16.4$ in the year 2016 but the difference was not significant ( $\mathrm{t}$-test $=2.1$ ) at $\mathrm{P}>0.05$.

- In the MIC: the prevalence of anaemia among women in the reproductive age group (15-49 years) decreased from a mean of $34.03 \pm 5.8$ in the year 2000 to a mean of $33.74 \pm 6.3$ in the year $2016(\mathrm{t}$-test $=0.11)$ at $\mathrm{P}>0.05$. While the prevalence of anaemia in CU5 dropped significantly from a high mean of 50.5 \pm 13.6 in the year 2000 to a mean of $34.4 \pm 11.2$ in the year 2016, which was statistically significant ( $\mathrm{t}$-test $=3.03$ ) at $\mathrm{P}<0.01$.

- In the HIC: the prevalence of anaemia among women in the reproductive age group (15-49 years) decreased from a mean of $34.6 \pm 10.01$ in the year 2000 to a mean of $33.7 \pm 8.3$ in the year 2016. The difference was not significant (t-test $=0.17$ ) at $\mathrm{P}>0.05$. While the prevalence of anaemia in CU5 dropped from a mean of $44+9.6$ in the year 2000 to a mean of $30.67 \pm 5.9$ in the year 2016 which was statistically significant $(\mathrm{t}=$ 2.89) at $\mathrm{P}<0.02$.

II- Growth and nutritional indices with anaemia: Country data for the prevalence of anaemia in women (15-49 years of age) and anaemia in the CU5 were correlated with the prevalence of LBW, stunting, overweight and obesity in CU5 and in adults in the EMR countries as shown in table (2) as follows:

- There was a significant relationship between prevalence of NAP with LBW rates, stunting and NA in CU5 (r0.72, r0.81, r0.74 respectively at $\mathrm{P}<0.001$ (for all values). 
While there was a negative significant relationship between NAP with overweight and obesity in CU5 (r-0.62, $\mathrm{r}-0.53)$ at $\mathrm{P}<0.01$ and $\mathrm{P}<0.01$ respectively.

- There was a significant relationship between the prevalence of NANP (15-49 years) and prevalence rates of LBW, stunting and anaemia in CU5 (r0.72, r0.70, r0.52 at $\mathrm{P}<0.001$, $\mathrm{P}<0.001$ and $\mathrm{P}<0.01$ respectively). There was a negative significant relationship between prevalence of anaemia during pregnancy with overweight and obesity in CU5 ( $\mathrm{r}-0.44, \mathrm{r}-$ 0.47 ) at $\mathrm{P}<0.01$ and $\mathrm{P}<0.01$ respectively.

- There was a significant relationship between NA in CU5 with prevalence of LBW and stunting ( $\mathrm{r} 0.66, \mathrm{r} 0.72$ ) at $\mathrm{P}<0.001$ and $\mathrm{P}<0.001$ respectively. There was some relationship between NA in CU5 with overweight and obesity in the same age group but this was not statistically significant $(\mathrm{r}-0.31, \mathrm{r}-0.35)$ at $\mathrm{P}>0.05$ and $\mathrm{P}>0.05$ respectively.

III- Anaemia and mortality: prevalence rates of NAP, NANP were highly correlated with NMR, IMR, U5MR, MMR and NCD related mortality for all 22 countries of the EMR as shown in table (3) as follows:

- NMR for all 22 countries were significantly correlated with NAP, NANP and NA in CU5 (r0.73, r0.66 and $\mathrm{r} 0.63$ ) at $\mathrm{P}<0.001, \mathrm{P}<0.001$ and $\mathrm{P}<0.001$ respectively.

- Infant mortality rates (IMR) for all 22 countries were significantly correlated with NA NAP, NANP and NA in CU5 (r0.9, r0.62 and r0.9) at $\mathrm{P}<0.001, \mathrm{P}<0.01$ and $\mathrm{P}<0.001$ respectively.

- Under five mortality rate (U5MR) for all 22 countries were significantly correlated with NAP, NANP and NA in CU5 (r0.7, r0.9 and r0.73) at $\mathrm{P}<0.001, \mathrm{P}<0.001$ and $\mathrm{P}<0.001$ respectively.

- Maternal mortality ratio (MMR) for all 22 countries were significantly correlated with NAP, NANP and NA in CU5 (r0.72, r0.39 and r0.56) at $\mathrm{P}<0.001, \mathrm{P}>0.05$ and $\mathrm{P}<0.01$ respectively.

- NCD related mortality for all 22 countries were significantly correlated with NAP, NANP and NA in CU5 (r0.7, r0.9 and r0.73) at $\mathrm{P}<0.001, \mathrm{P}<0.001$ and $\mathrm{P}<0.001$ respectively.

IV- Breastfeeding rates and anaemia: There was a relationship between anaemia prevalence in pregnant, non-pregnant women and in CU5 age group with continued breastfeeding rates for 12 and 24 months (CB12), (CB24) but not with breastfeeding rates for timely initiation (TFS) and EBF as shown in table (4) as follows:

- There were significant relationships between CB12 and NAP and LBW (r0.49 and 0.48) at $\mathrm{P}<0.01$ and $\mathrm{P}<0.01$ respectively. The relationship between $\mathrm{CB} 12$ and anaemia in CU5 was not significant (r0.36) at $\mathrm{P}>0.05$, but became significant with breastfeeding for two years $(\mathrm{r} \mathrm{CB} 24=0.46)$ at $\mathrm{P}<0.01$.

- There was also a significant relationship between continued breastfeeding rates for 24 months and NAP and LBW ( $\mathrm{r} 0.51$ and 0.52 ) at $\mathrm{P}<0.01$ and $\mathrm{P}<0.01$ respectively.

- There was no significant correlation of NAP, NANP or CU5 with TFS or EBF $(\mathrm{P}>0.05)$.

V- Breastfeeding continuity and income groups: The relationship between anaemia in pregnant, non-pregnant and CU5 with BF12 and BF24, by income level in EMR countries, is shown in table (5) as follows: 
- In the LIC: There was a significant negative correlation of NAP with BF12 (r-0.46) and to 24 months $(\mathrm{r}-0.65)$ at $\mathrm{P}<0.01$ and $\mathrm{P}<0.001$ respectively. However there was a significant positive correlation of NANP with BF12 (r0.87) and BF24 (r0.65) at $\mathrm{P}<0.001$ and $\mathrm{P}<0.001$ respectively. There was no correlation between the breastfeeding duration and anaemia in CU5 ( $\mathrm{P}>0.05)$.

- In the MIC: Anaemia in pregnant women correlated poorly with BF12 (r0.35) at $\mathrm{P}>0.05$. But the relationship was stronger with $\mathrm{BF} 24$ (r0.79) at $\mathrm{P}<0.001$. Also there was a significant positive correlation of NAP with breastfeeding BF12 (r-0.7) and BF24 (r0.46) at $\mathrm{P}<0.001$ and $\mathrm{P}<0.01$ respectively. There was also a significant correlation between anaemia in CU5 with BF12 (r0.56) at $\mathrm{P}<0.01$ and to BF24 (r0.8) at $\mathrm{P}>0.001$.

- In the HIC: There were significant correlations of NAP with BF12 (r0.43) $\mathrm{P}<0.01$ only but not to 24 months (r0.08) $\mathrm{P}>0.05$. However there was also a poor positive correlation of NANP with BF12 (r0.36) at $\mathrm{P}>0.05$. But it became significant at BF24 (r0.73) at $\mathrm{P}<0.001$. Anaemia in CU5 was significantly correlated with $\mathrm{BF} 12$ ( $\mathrm{r} 0.59)$ at $\mathrm{P}<0.01$ and $\mathrm{BF} 24$ (r0.56) at $\mathrm{P}<0.01$.

\section{Discussion}

Anaemia has remained a widespread public health problem in EMR countries. In early 2000 the prevalence ranged from $17 \%$ to over $70 \%$ among preschool children; from $14 \%$ to $42 \%$ among adolescents and from $11 \%$ to over $40 \%$ among women of childbearing age ${ }^{(4)}$.

Our current study showed that prevalence of anaemia in women, 15 to 49 years age group, has not changed from 2000 to 2016 exhibiting a downward shaped curve in 16 out of the 22 countries of the region (72\%). This pattern was highly correlated with indices of nutritional status of children and adults, particularly stunting and overweight. The highest correlations were evident with LBW, stunting in CU5 and overweight in adults. These correlations were similar for pregnant and non-pregnant women substantiating the findings of other workers ${ }^{(14)}$ who showed that anaemia affects pregnancy outcome depending on the prepregnant and early pregnancy state of anaemia and although it increases during pregnancy, its ultimate outcome is determined by its prepregnant state ${ }^{(\mathbf{1 4})}$.

Both iron deficiency (ID) and excess iron can lead to impaired health status. There is substantial evidence of a U-shaped curve between the risk of adverse birth outcomes and maternal hemoglobin concentrations during pregnancy ${ }^{(22)}$. Higher rates of preterm deliveries ( $<37$ weeks gestation) and LBW were found among patients with anaemia as compared to non-anemic women. Higher rates of cesarean section were found among anemic women. When detected early in pregnancy, IDA is associated with an over 2-fold increase in the risk of preterm delivery but with no adverse perinatal outcome ${ }^{(22)}$. While other studies have 
shown that iron supplementation to pregnant women, even without anaemia, is associated with a lower risk of LBW ${ }^{(13)}$.

On the other hand excess iron during pregnancy may have adverse effects on birth outcomes, including oxidative stress, increased blood viscosity, and impaired systemic response to inflammation and infection (14). High levels of hemoglobin, hematocrit, and ferritin are associated with an increased risk of fetal growth restriction, preterm delivery, and preeclampsia. Iron supplements and increased iron stores have recently been linked to maternal complications as gestational diabetes ${ }^{(\mathbf{1 9})}$. In controversy, clinical trials in the United States and in Nepal that involved early supplementation with iron showed some reduction in risk of LBW, but not preterm delivery. During the 3rd trimester, maternal anaemia may simply be an indicator of an expanded maternal plasma volume which may not warrant treatment. Consequently, while iron supplementation may improve pregnancy outcome when the mother is iron deficient, it is also possible that prophylactic supplementation may increase risk when the mother does not have iron deficiency or IDA ${ }^{(\mathbf{1 2})}$.

Studies in developing countries show that women treated throughout pregnancy for IDA had improvements in iron status that were significant in those with low haemoglobin $(\mathrm{Hb})$ at baseline and there was a $24 \%$ reduced risk of perinatal mortality and a $23 \%$ reduced risk of early infant mortality with increase in indices. Nevertheless compliance with the iron intake is a problem ${ }^{(23)}$. Other authors ${ }^{(24,25)}$ recommend that iron supplements should not be taken by pregnant women whose $\mathrm{Hb}$ levels exceed $11 \mathrm{~g} / 100 \mathrm{ml}$ during the $1 \mathrm{st}$ and 3rd trimesters and $10.5 \mathrm{~g} / 100 \mathrm{ml}$ during the $2 \mathrm{nd}$ trimester. This is supported by randomised double-blind placebo-controlled trials ${ }^{(24,25)}$.

In this study NA in pregnant was highly correlated with anaemia in CU5. Although studies show that hemoglobin concentrations in early pregnancy, but not in later pregnancy, are linked with adverse outcomes, we would have expected to see that the trends in NA in CU5 follow the same pattern as anaemia in women. On the contrary trends in NA among CU5 showed a $30 \%$ reduction of NA in almost all the countries in the EMR (except Yemen). Other workers have shown that one half of the newborns who were anaemic were born to anemic mothers. Maternal iron deficiency anaemia (mild to moderate) can affect the blood profile and iron concentrations in umbilical cord blood of newborns, but does not interfere with the child's anthropometric parameters. Hence anaemia in pregnancy may increase the risk of anaemia in the newborn only when severe ${ }^{(26)}$. 
In this study we found high correlations between NAP and stunting in CU5. Other studies (27) report that maternal anaemia may increase the risk of stunting in affected populations. Serum iron measurement should not be used as the only marker for diagnosis, as other underlying causes may coexist that produce anaemia and stunting. However administration of iron supplements in the antenatal period and after birth or miscarriage is needed to replenish iron stores $\mathbf{( 2 8 , 2 9 )}$.

Our findings showed improvement of iron status with extended breastfeeding for two years. This was shown by the positive correlation between BF24 and NANP women. However, the increase of IDA with prolonged breastfeeding in pregnant women is expected. We found a positive correlation of anemia with TFR which indicates that repeated pregnancies and shortened duration of breastfeeding may deplete iron stores, aggravating IDA. While prolonged breastfeeding with inappropriate weaning foods may predispose to NA in children. Breast milk iron content may be significantly reduced in severely, but not mildly or moderately, anaemic mothers. Breastfeeding supports iron absorption and uptake and can be protective against anaemia ${ }^{(\mathbf{1 4}, \mathbf{1 5})}$. Other studies ${ }^{(27)}$ have shown that breast milk iron levels correlated with maternal hemoglobin and iron levels but not with ferritin levels. Moreover maternal anthropometry had significant correlations with indices of iron nutriture in maternal and cord blood but showed no relationship with breast milk iron content. Placental weight was comparable between anemic and nonanemic mothers. Hence maternal suboptimum nutritional status, when severe, exerts a significant influence on fetal iron status but has little influence on breast milk iron content ${ }^{(30)}$.

In our study NA was significantly associated with maternal and child mortality indicating that correcting anaemia early before conception may reduce mortality, especially when continued breastfeeding is encouraged. Other workers (31, 32) have shown that. Hence continued breastfeeding plays a protective role and may possibly reduce the magnitude of poor outcome of anaemia on pregnancy and child survival. This was more evident among the LIC who continue breastfeeding with high intensity in the second year. Unlike the MIC and HIC who wean early off the breast and rely more on feeding milk and other foods that predispose children to obesity and decrease mother's ability to continue breastfeeding for two years. Another key determinant for anaemia prevalence may be linked to high TFR and short interpregnancy intervals ${ }^{(33)}$.

EBF for six months has been shown to have short and long-term outcomes on the health, growth and development of children and young adults ${ }^{(34,35)}$. There is also growing evidence 
that CBF for two years may also have long term protective effects on the health of mothers and breastfed children as adults ${ }^{(36)}$ and also against NA ${ }^{(37)}$. However there is a great deal of controversy $(\mathbf{1 0}, \mathbf{1 1}, \mathbf{1 2})$ around the iron status of babies who are EBF in the first six months and those who continue to breastfeed after the introduction of foods regarding needs for supplementation of infants and mothers. There were no significant correlations between TFS, EBF and anaemia. These indicators are important as they reduce serious infectious diseases $(34,35)$ and thereby reduce NA. Whereas early introduction of cow's milk-based foods may increase NA by inducing cow's milk allergy ${ }^{(18)}$.

Other workers ${ }^{(36)}$ have shown that obesity can increase the risk of developing IDA, possibly through circulating hepcidin levels and decreased bioavailability of iron ${ }^{(37)}$. Breastfeeding may also have a protective role against anaemia by preventing overweight and obesity $\mathbf{( 3 8 , 3 9}$, 40). Our study showed a significant correlation of anemia among women and children with overweight and obesity.

With the surmounting challenges facing countries in the EMR especially the high prevalence of IDA and obesity, optimal breastfeeding practices by increasing EBF rates and increasing mean duration of breastfeeding, can be a cost effective intervention for supporting maternal and child survival. Our study has shed some light on these problems and has shown that NAP, NANP and CU5, in the EMR countries preexist with other problems as overweight and obesity which are aggravated by suboptimal breastfeeding practices especially discontinuation of breastfeeding before 2 years irrespective of income group.

Conclusions: Iron deficiency is the highest prevailing nutritional deficiency which hits mostly the lower middle income populations with a prevalence of $42.5 \%{ }^{(28)}$. Trend analysis revealed a U-shaped curve ${ }^{(14)}$ which correlates with the high rates of LBW in EMR. Hence iron supplementation may improve LBW especially in LIC. Moreover, high prevalence of infectious diseases and malnutrition particularly in the LIC, and overweight and obesity, in MIC and HIC, can explain the disturbing trends in NA.

Iron supplementation may be needed for pregnant women on the one hand, while prolonging breastfeeding may be required for the non-pregnant (nursing mothers) to protect them against anaemia when they do get pregnant. Also supplementing infants in the second year may be needed, along with increasing the intake of iron rich foods. On the other hand, encouraging women to continue breastfeeding into the second year can decrease the burden of IDA in infants by reducing the exposure to infectious diseases and obesity in women and infants. Supporting continued breastfeeding for two years and birth spacing $(33,41,42)$ can improve the burden of NA in EMR countries $\mathbf{( 4 3 , 4 4 )}$. 


\section{References}

1- WHO. Worldwide prevalence of anaemia 1993-2005: WHO global database on anaemia. Geneva: World Health Organization 2008.

2- Kassebaum NJ; GBD 2013 Anaemia collaborators. The global burden of anaemia. Hematol Oncol Clin North Am. 2016; 30(2):247-308. Doi:10.1016/j.hoc.2015.11.002.

3- Verster A, van der Pols JC. Anaemia in the Eastern Mediterranean Region. Eastern Mediterranean Health Journal, 1995, 1:64-79. [L'anémie dans la Région de la Méditerranée orientale. Résumé p.64]

4- Bagchi K. Iron deficiency anaemia--an old enemy. East Mediterr Health J. 2004 Nov;10(6):754-60.

5- Habibzadeh F. Anaemia in the Middle East. Lancet. 2012; 379: 1.

6- WHO. Consideration of the evidence on childhood obesity for the Commission on Ending Childhood Obesity: report of the Ad hoc Working Group on Science and Evidence for Ending Childhood Obesity. Geneva: World Health Organization, 2016.

7- Han Z, Mulla S, Beyene J, Liao G, McDonald SD. Maternal underweight and the risk of preterm birth and low birth weight: a systematic review and meta-analyses. Int J Epidemiol 2011; 40: 65-101. 2

8- Black RE, Victora CG, Walker SP, et al. Maternal and child undernutrition and overweight in low-income and middle-income countries. Lancet 2013; 382: 427-51.

9- Chantry CJ, Howard CR, Auinger P. Full breastfeeding duration and risk for iron deficiency in U.S. infants. Breastfeed Med. 2007 Jun;2(2):63-73.

10- Maguire JL, Salehi L, Birken CS, Carsley S, Mamdani M, Thorpe KE, Lebovic G, Khovratovich M, Parkin PC; TARGet Kids! collaboration. Association between total duration of breastfeeding and iron deficiency. Pediatrics. 2013 May;131(5):e1530-7. doi: 10.1542/peds.2012-2465.

11- Marquis GS, Habicht JP, Lanata CF, Black RE, Rasmussen KM. Association of breastfeeding and stunting in Peruvian toddlers: an example of reverse causality. Int J Epidemiol. 1997 Apr;26 (2):349-56.

12- Scholl TO. Iron status during pregnancy: setting the stage for mother and infant.Am J Clin Nutr. 2005 May;81(5):1218S-1222S.

13- Palma S, Perez-Iglesias R, Prieto D, Pardo R, Llorca J, Delgado-Rodriguez M. Iron but not folic acid supplementation reduces the risk of low birthweight in pregnant women without anaemia: a case-control study. J Epidemiol Community Health. 2008 Feb;62(2):120-4.

14- Dewey KG, Oaks BM. U-shaped curve for risk associated with maternal hemoglobin, iron status, or iron supplementation. Am J Clin Nutr. 2017 Dec;106(Suppl 6):1694S-1702S. doi: 10.3945/ajcn.117.156075. Epub 2017 Oct 25.

15- Dewey KG, Chaparro CM. Session 4: Mineral metabolism and body composition iron status of breastfed infants. Proc Nutr Soc. 2007;66(3):412-22. Doi10.1017/S002966510700568X.

16- Oski FA, Landaw SA. Inhibition of iron absorption from human milk by baby food.Am J Dis Child. 1980;134(5):459-60.

17- Sridhar A, Salcedo J. Optimizing maternal and neonatal outcomes with postpartum contraception: impact on breastfeeding and birth spacing. Maternal Health, Neonatology and Perinatology. 2017;3:1. doi:10.1186/s40748-016-0040-y.

18- Jiang T, Jeter JM, Nelson SE, Ziegler EE. Intestinal blood loss during cow milk feeding in older infants: quantitative measurements. Arch Pediatr Adolesc Med. 2000;154(7):673-8. Doi10.1017/S0022-3476(99)70091-0. 
19- World Health Organization (WHO), Eastern Mediterranean Region (EMR) Framework for health information systems and core indicators for monitoring health situation and health system performance for 2017 for the 22 countries of the EMR region.

20-UNICEF. Muticenter Cluster Surveys for monitoring country data. Available at www.unicef.mics.org. 2016.

21-WHO. World Health Statistics 2016 Monitoring Health for the SDGs. (Sustainable Development Goals). World Health Organization, Geneva, Switzerland 2016.

22- Stevens GA et al. Global, regional, and national trends in hemoglobin concentration and prevalence of total and severe anaemia in children and pregnant and non-pregnant women for 1995-2011: a systematic analysis of population-representative data. The Lancet Global Health 2013;1:e16-e25.

23- Abioye AI, Aboud S, Premji Z, Etheredge AJ, Gunaratna NS, Sudfeld CR, et al. Iron supplementation affects hematologic biomarker concentrations and pregnancy outcomes among iron-deficient Tanzanian women. J Nutr. 2016 Jun;146(6):1162-71. doi: 10.3945/jn.115.225482. Epub 2016 Apr 2.

24- Editorial. Non-anaemic pregnant women should not take iron supplements. Prescrire Int. 2009 Dec;18(104):261-2.

25- Scanlon KS, Yip R, Schieve LA, Cogswell ME. High and low hemoglobin levels during pregnancy: differential risks for preterm birth and small for gestational age.Obstet Gynecol. 2000 Nov;96 (5 Pt 1):741-8.

26- de Sá SA, Willner E, Duraes Pereira TA, de Souza VR, Teles Boaventura G, Blondet de Azeredo V. Anaemia in pregnancy: impact on weight and in the development of anaemia in newborn. Nutr Hosp. 2015 Nov 1;32(5):2071-9. doi: 10.3305/nh.2015.32.5.9186.

27- Lelic M, Bogdanovic G, Ramic S, Brkicevic E.Influence of maternal anaemia during pregnancy on placenta and newborns. Med Arch. 2014 Jun;68(3):184-7. doi: 10.5455/medarh.2014.68.184-187. Epub 2014 .

28- World Health Organization. Hemoglobin concentrations for the diagnosis of anaemia and assessment of severity. Vitamin and mineral nutrition information system. Geneva: World Health Organization, 2011.

29- Montoya Romero Jde J, Castelazo Morales E, Valerio Castro E, Velázquez Cornejo G, Nava Muñoz DA, Escárcega Preciado JA, et al. [Review by expert group in the diagnosis and treatment of anaemia in pregnant women. Federación Mexicana de Colegios de Obstetricia y Ginecología].Ginecol Obstet Mex. 2012 Sep;80(9):563-80.

30- Kumar A, Rai AK, Basu S, Dash D, Singh JS. Cord blood and breast milk iron status in maternal anaemia. Pediatrics. 2008 Mar;121(3):e673-7.

31- Brabin B.J., Premji Z., Verhoeff F. An analysis of anemia and child mortality. J Nutr. 2001; 131(2s-2):636S-645S; discussion 646S-648S.

32- Scott S.P., Chen-Edinboro L.P., Caulfield L.E., Murray-Kolb L.E. The impact of anaemia on child mortality: an updated review. Nutrients. 2014;6(12):591532.doi:10.3390/nu6125915.

33-Okwu GN; Ukoha AI. Studies on the predisposing factors of iron deficiency anaemia among pregnant women in a Nigerian community. Pakistan Journal of Nutrition. 2008 Jan-Feb; 7(1):151-156. 
34- Azuine RE, Murray J, Alsafi N, Singh GK. Exclusive breastfeeding and under-Five mortality, 2006-2014: A Cross-National Analysis of 57 Low- and-Middle Income Countries. International journal of MCH and AIDS. 2015;4(1):13-21.

35-Sankar, M. J., Sinha, B., Chowdhury, R., Bhandari, N., Taneja, S., Martines, J. and Bahl, R. Optimal breastfeeding practices and infant and child mortality: a systematic review and meta-analysis. Acta Paediatr. 2015;104: 3-13. doi:10.1111/apa.13147.

36- Cepeda-Lopez AC, Aeberli I., Zimmermann MB. Does obesity increase risk for iron deficiency? A review of the literature and potential mechanisms. Int J Vit Nutr Res. 2010;80(45):263-70.

37-Aeberli I., Hurrel RF., Zimmermann MB. Overweight children have higher circulating hepcidin concentrations and lower iron status but have dietary iron intakes and bioavailability comparable with normal weight children. Int J Obes (Lon) 2009;33(10):1111-17. Doi:10.1038/ijo.2009.146.

38-Yan J., Liu L., Zhu Y., Huang G., Wang PP. The association between breastfeeding and childhood obesity: a meta-analysis. BMC Public Health 2014:14:1267-1278.

39-Kramer M.S., Matush L., Vanilovich I., Platt RW., Bogdanovich N., Sevkovskaya Z., et al. Effects of prolonged and exclusive breastfeeding on child height, weight, adiposity and blood pressure at age 6.5: evidence from a large randomized trial. Am J Clin Nutr 2007;86:1717-1721.

40-Victora CG, Bahl R, Barros AJ et al. Breastfeeding in the 21st century: epidemiology, mechanisms, and lifelong effect. Lancet. 2016 Jan 30;387(10017):475-90. doi: 10.1016/S0140-6736(15)01024-7.

41- Dewey KG, Cohen RJ. Does birth spacing affect maternal or child nutritional status? A systematic literature review. Matern Child Nutr. 2007 Jul; 3(3):151-73. PMID: 17539885 [PubMed - indexed for MEDLINE].

42- Conde-Agudelo A., Rosas-Bermudez A., Castaño F, and Norton M.H. Effects of Birth Spacing on Maternal, Perinatal, Infant, and Child Health: A Systematic Review of Causal Mechanisms. Studies in Family Planning. June 2012; 43 (2): 93-114.

43-Howie PW. Breastfeeding: a natural method for child spacing. Am J Obstet Gynecol. 1991 Dec;165(6 Pt 2):1990-1.

44-World Health Organization (WHO). Nutritional anaemias. Tools for effective prevention and control. Geneva: WHO; 2017. 